\title{
CARACTERIZAÇÃO PRELIMINAR DA COBERTURA VEGETAL EM UM MUNICÍPIO SUSCEPTÍVEL A DESERTIFICAÇÃO (CAICÓ - RN)
}

\author{
Denise Santos Saldanha ${ }^{(a)}$, Paulo Jerônimo Lucena de Oliveira ${ }^{(b)}$, Jânio Carlos Fernandes \\ Guedes ${ }^{(\mathrm{c})}$, Diógenes Félix da Silva Costa ${ }^{(\mathrm{d})}$
}

(a) Grupo de Pesquisa em Geoecologia e Biogeografia de Ambientes Tropicais - TRÓPIKOS /UFRN, denisesaldanha.lama@gmail.com

(b) Grupo de Pesquisa em Geoecologia e Biogeografia de Ambientes Tropicais - TRÓPIKOS /UFRN, paulojeronimo.geo@gmail.com

${ }^{\text {(c) }}$ Grupo de Pesquisa em Geoecologia e Biogeografia de Ambientes Tropicais - TRÓPIKOS /UFRN, janiocf.guedes@gmail.com

${ }^{(d)}$ Líder do TRÓPIKOS/UFRN, diogenes.costa@pq.cnpq.br

\section{EIXO: BIOGEOGRAFIA, MANEJO DE ÁREAS NATURAIS E PROTEGIDAS: CONSERVAÇÃO DA BIODIVERSIDADE}

\begin{abstract}
Resumo:
A Desertificação na região semiárida nordestino é um processo que ocorre desde da sua colonização por fatores naturais ou antrópicos de grande perda ecológica e também social. A Desertificação atinge principalmente o Bioma Caatinga, sendo esse Bioma totalmente brasileiro que ocupa toda a região nordeste. O município de Caicó está localizado na Microrregião do Seridó Ocidental do Estado do Rio Grande do Norte com proximadamente $1.228,576 \mathrm{~km}^{2}$. Todo o material cartográfico foi elaborado a partir da fusão de imagens do satélite Landsat 8 (sensores OLI "Operational Land Imager", órbita 215, pontos 064 e 065 de 01/06/2013, resolução espacial de 30 metros. Como resultado, foi possível identificar quatros tipos de classes de cobertura vegetal, onde as mesmas foram divididas em Caatinga densa, Caatinga rala, Corpos d'água e solo exposto. Assim, o uso das geotecnologias mostraram-se eficientes na distribuição e espacialização da cobertura vegetal podendo servir para identificação de áreas em desertificação.
\end{abstract}

Palavras chave: Desertificação no Seridó; Caatinga; Semiárido Nordestino.

\section{Introdução}

No Brasil, as áreas suscetíveis à Desertificação abrange todo o trópico semiárido, ocupando aproximadamente $1.340 .000 \mathrm{~km}$, chegando a ter $180 \mathrm{mil} \mathrm{km}^{2}$, essa dessertificação acontece principalmente no nordeste brasileiro, que possui 55,25\% do seu território atingido em diferentes níveis de deterioração ambiental (SANTANA, 2007).

Com uma cultura de criadores de bovinos e caprinos que foi implantada desde do período da colonização do Seridó (por volta de 1700), a FAO (Food and Agriculture Organization) considera esses animais como um agentes promotores de desertificação nas regiões semiáridas do planeta (FAO 1993). 
A desertificação é um processo contínuo no Bioma Caatinga, pois como afirma Tabarelli et al. (2000) que apesar da sua significativa extensão territorial, tem uma valorosa importância sócio-econômica em ser o único bioma totalmente restrito ao território nacional, a caatinga é o bioma menos protegido em relação ao biomas existentes no Brasil, com menos de $2 \%$ de sua área estando protegidos em unidades de conservação de proteção integral.

A fim de avaliar os processos de uso ocupação do solo do respectivo município, o objetivo do trabalho tem como foco caracterizar a cobertura vegetal do município de Caicó/RN, que se encontra susceptível a desertificação, servindo de ferramenta para o planejamento ambiental bem como servir de instrumento para tomada de decisão municipal.

Dessa forma, o presente trabalho aborda métodos de análise e mapeamento da cobertura vegetal em ambiente de Sistema de Informações Geográficas (SIG), utilizando-se de técnicas de geoprocessamento, já que o mesmo mostra-se relevante para o diagnóstico inicial que precede a análise sistêmica do meio físico do ambiente em estudo (OLIVEIRA \& CESTARO, 2012).

\section{Metodologia}

O município de Caicó está localizado na Microrregião do Seridó Ocidental do Estado do Rio Grande do Norte, entre o par de coordenadas $\left(6^{\circ} 27^{\prime} \mathrm{S}\right.$ de latitude), ( $37^{\circ} 5^{\prime} \mathrm{O}$ de longitude) com aproximadamente $1.228,576 \mathrm{~km}^{2}$. Segundo o (IDEC, 1991), o clima da região, de acordo com a classificação de Köppen, é do tipo Bsh: semiárido quente, com precipitação pluviométrica média anual baixa $(<800 \mathrm{~mm})$ e uma estação acentuadamente seca, apresentando um dos climas mais quentes e secos do Nordeste brasileiro, com temperatura média anual acima de $27,4^{\circ} \mathrm{C}$.

Todo o material cartográfico foi elaborado a partir da fusão de imagens do satélite Landsat 8 (sensores OLI “Operational Land Imager", órbita 215, pontos 064 e 065 de 01/06/2013, resolução espacial de 30 metros, onde, depois de gerado a composição de bandas, (RGB, bandas 7.5.3 respectivamente) a mesma passou por técnicas de fusão de bandas, nesse caso, a imagem gerada em falsa cor, foi fusinada junto com a banda PAN "Pancromática" de resolução espacial de 15 metros para obter-se maior riquesa de detalhes nas mesmas.

Essas por sua vez são disponibilizadas gratuitamente pelo Instituto Nacional de Pesquisas Espaciais INPE, e também pela National Aeronautics and Space Administration - NASA, as quais passaram por um processo de fusão de bandas no software Arcgis 10.1 (versão acadêmica), a partir do qual foi obtida uma imagem resultante em falsa cor (Red-Green-Blue) com resolução espacial de 15 metros. 
Assim como a utilização de uma imagem SRTM (Shuttle Radar Topography Mission), referente à área de estudo, ou seja, foi utilizada a imagem SB-24-Z-B, na qual encontra-se inserido o município de Caicó, essa imagem também disponibilizada gratuitamente pela National Aeronautics and Space Administration - NASA.

Toda a delimitação das classes de ocupação, produção de material cartográfico digital e Processamento Digital de Imagens de sensoriamento remoto foram realizados com o auxílio do software Envi 4.7 e o layout final no Arcgis 10.1, finalizando-se as atividades com a elaboração de mapas das diferentes classes de ocupação do solo presentes na área. No Envi 4.7 foram realizados o realce de contraste das imagens de satélite, mapeamento e produção do material cartográfico. As cenas foram mosaicadas em ambiente de Sistema de Informação Geográfica (SIG), bem como todo o processo de manipulação e integração dos dados espaciais. Para a tabulação e armazenamento dos dados foi utilizado o software Microsoft Excel 2013.

A classificação fitogeográfica foi realizada com visitas in loco, e com a caracterização foi possível identificar o extrato vegetal da área (caatinga herbácea, caatinga arbustiva arbórea e caatinga arbustiva) de acordo com o porte de cada espécie. Estes ambientes são caracterizados com espécies xerófitas de baixo e médio porte, com a vegetação espaçada.

\section{Resultado e Discussão}

A partir do mapeamento de uso e ocupação do solo do município de Caicó - RN foi possível identificar quatros tipos de classes de cobertura vegetal, onde as mesmas foram divididas em Caatinga densa com uma de aproximadamente 20.380,7 hectares, Caatinga rala, aproximadamente 26316,8 hectares, Corpos d'água 1142,5 hectares, e solo exposto 55000,0 hectares respectivamente, como mostra a figura abaixo (Figura. 1).

Onde depois de processadas as imagens os dados foram organizados em uma tabela para melhor análise dos mesmos (Tabela I). 

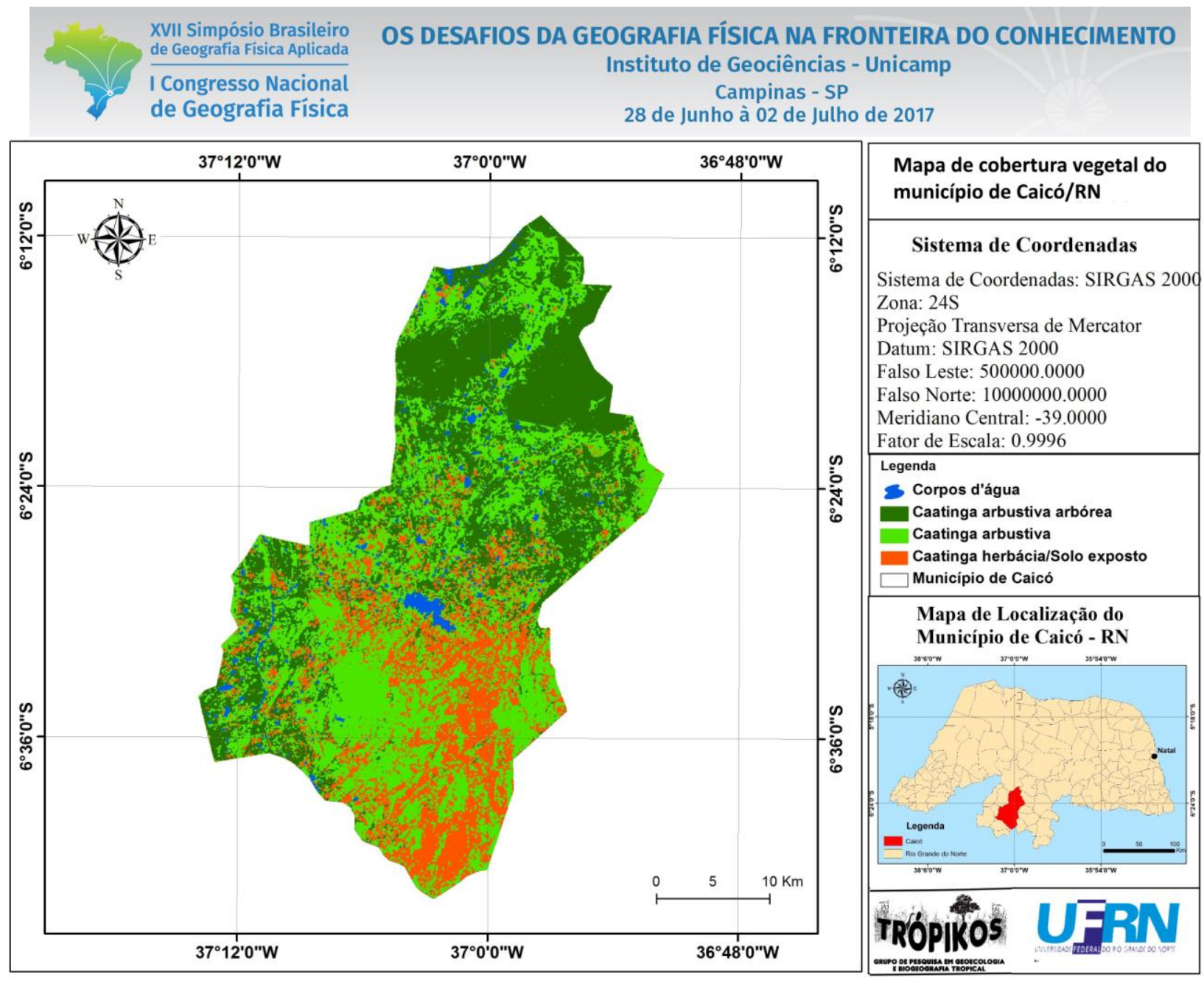

Figura 1 - Mapa de cobertura vegetal do município de Caicó - RN

Tabela I - Classes de cobertura vegetal

\begin{tabular}{|c|c|c|}
\hline Classes de uso & $\begin{array}{c}\text { Valor em hectares } \\
\text { (ha) }\end{array}$ & $\begin{array}{c}\text { Valor em } \\
\text { porcentagem }(\boldsymbol{\%})\end{array}$ \\
\hline Vegetação arbustiva arbórea & 27793,2 & 27,8 \\
\hline Vegetação arbustiva & 41637,7 & 36,0 \\
\hline Vegetação herbácea/ Solo exposto & 40295,8 & 35,1 \\
\hline Corpos d'água & 1142,5 & 1,1 \\
\hline
\end{tabular}

De acordo com os dados da tabela (Tabela I), percebe-se que a cidade de Caicó/RN apresenta uma grande semelhança na sua cobertura vegetal, sendo bem distribuida em todo o municipio. $\mathrm{O}$ extrato arbustivo corresponde a 36\%, apresenta um porte médio (Ex: Jurema Preta/ Mimosa tenuiflora), a vegetação herbácea corresponde a 35\%, são de pequeno porte e é muito encontrada na região do Seridó, como por exemplo, xique-xique/Pilosocereus gounellei, já o estrato arbustivo arbóreo apresenta 27,8\% e com apenas $1,1 \%$ são os corpos d' água do município, tornando- o um local susceptível a desertificação. 
Vale frisar que os dados de uso e ocupação do solo obtidos a partir da imagem do Satélite Landsat 8 no período de Junho de 2013 expostos na tabela acima, refere-se a um periodo de estiagem, ou seja, de acordo com classificação climática de Koppen, o município de Caicó está inserido em uma zona onde a precipitação média é de $>800$ mm anuais.

\section{Considerações Finais}

Diante do mapeamento elaborado, a partir da imagem SRTM, foi possível classificar a cobertura vegetal no município de Caico/RN. Conclui-se então, que o uso das geotecnologias mostraram-se eficientes na distribuição e espacialização da cobertura vegetal, além de constituir como uma ferramenta de grande importância na identificação de áreas propicias a dessertifcação.

\section{Referências}

FAO. 1993. El papel de los animales domesticos en el control de la desertificacion. PNUD/FAO, Oficina Regional de La Fao para America Latina Y el Caribe, Santiago.

FARIA, O. L. E depois... In: Os Açudes dos Sertões do Seridó. Coleção Mossoroense. Vol. LVI. Natal, 1978. p. 24-40.

IDEC. Açudes Públicos do Rio Grande do Norte. Características Físicas e Técnicas - Fundação Instituto de Desenvolvimento do Rio Grande do Norte. Natal/RN, 1991.

OLIVEIRA, A. V. L. C.; CESTARO, L. A. Caracterização do meio físico para subsidiar um zoneamento geoambiental do município de Currais Novos - RN - Brasil. Revista Geonorte. Edição Especial. Amapá. 2012.

SANTANA, M. O. (org.) Atlas de áreas susceptíveis à desertificação no Brasil. Brasília/DF: Ministério do Meio Ambiente, 2007.

SOUZA, E. Milagres da Açudagem. In: GUERRA, Otto (org.). Vigésimo livro das secas. p. 72-75. Col. Mossoroense. 1989.

TABARELLI, M.; SILVA, J. M. C.; SANTOS, A. M. Análise de representatividade das unidades de conservação de um direto e indireto na Caatinga: análise preliminar. In: Avaliação e identificação de ações prioritárias para a conservação, utilizando sustentável e repartição de benefícios da biodiversidade do bioma Caatinga: Petrolina, Pernambuco. 2000. P. 13. 